\title{
Emotional Intelligence and Psychological Well-Being among Hearing-Impaired: Does it Relates?
}

\author{
Najib Ahmad Marzuki ${ }^{1, *}$, Azlizamani Zubir@Salim¹ and Ummi Habibah Abd Rani ${ }^{1}$ \\ ${ }^{1}$ School of Applied Psychology, Social Work and Policy Universiti Utara Malaysia, Kedah, Malaysia
}

\begin{abstract}
This paper explores the relationship between emotional intelligence and psychological wellbeing among hearing-impaired students. Emotional intelligence consists of five dimensions namely intrapersonal, interpersonal, adaptability, stress management and general mood. A total of 130 hearingimpaired students were chosen as participants via simple random sampling at four polytechnics in Malaysia. The Bar-On Emotional Quotient: Short (EQ-i: S) and Ryff's Psychological Well-Being instruments were utilised to measure emotional intelligence and psychological well-being. It was found that in general, hearing impaired students have moderate emotional intelligence level and psychological well-being. Results also found that intrapersonal, interpersonal and adaptability dimensions correlated significantly with psychological well-being. No correlations were found between stress management and general mood dimensions with psychological well-being. Though limited by their ability to speak and to hear, emotional intelligence among hearing-impaired students does play a role in enhancing their individual capability to learn and to experience positive psychological well-being in life.
\end{abstract}

\section{Introduction}

World Health Organisation (WHO) has estimated that there are 328 million hearing-impaired adults in the world [1]. Hearing impairment is defined as an absolute or partial loss of the capacity to hear out of one or two ears and may be considered as either mild, moderate, severe or profound [2]. In Malaysia, 53,357 people with disability (hearing-impaired) have registered with the Department of Social Welfare. However, only 1 percent of the overall total of people registered has acquired education and continues their study in educational institutions that provide special education in Malaysia including polytechnics. Nevertheless, the special education to develop this particular group into individual with emotional and psychological stability could not be delivered effectively. Parents fear and anxiety of permitting their children to enrol in this special program hinders this group from improving their quality of life [3]. According to [4], hearing impairment is significantly associated with cognitive development, social and emotional aspect of an individual.
The hearing-impaired community often faces barrier and this contribute towards negative effects in terms of emotional and psychological development. In [5] as well as [6] stipulated that individuals with hearing impairment faces problems in communication and are not able to make themselves understood by normal person. This situation affects the social, emotional and cognitive development of the hearing-impaired [7] and play a pivotal role in their overall psychological wellbeing.

According to [8], the most important needs for the hearing-impaired is to enhance their capability of engaging with the larger community, sensitive to their own emotional and psychological needs and aware of effects of their actions to the community. In general, hearing-impaired students are different from normal students in terms of communication with others and this may influence their emotions. In [9] argued that the emotional and psychological issues among hearingimpaired in the education sector were given less attention and are less studied.

It is difficult to define precisely the meaning of emotional intelligence and psychological well-being among hearing-impaired. However, the underlying definitions should not be discriminated between normal individual and the hearing-impaired.

\footnotetext{
*Corresponding author: author@e-mail.org
} 
In defined emotional intelligence as the ability to perceive accurately, appraise and express emotion [10]; the ability to access and/or generate feelings when they facilitate thought; the ability to understand emotion and emotional knowledge; and the ability to regulate emotions to promote emotional and intellectual growth. In this study, emotional intelligence refers to the definition based on the measurement by [11]. It consists of five dimensions namely intrapersonal, interpersonal, adaptability, stress management and general mood.

In terms of psychological well-being, [12] perceived it as subjective satisfaction of an individual life while [13] defined it as a state that emerges from feeling of satisfaction with one's physical health and oneself as a person and with one's close interpersonal relationships. The psychological well-being definitions in this study refers to [14] dimensions of psychological well-being that combines self-acceptance, positive relations with others, autonomy, environmental mastery, purpose on life and personal growth.

This paper explores the level of emotional intelligence and psychological well-being among hearing impaired students as well as examining the relationship between dimensions of emotional intelligence and psychological well-being.

\subsection{Previous Studies}

A study by [15] on the psychological well-being of hearing-impaired students demonstrated low scores in dimensions of self-acceptance and positive relationship. On the other hand, [16] stated that no significant relationship was found between social relationship and psychological well-being among hearing-impaired students.

In a study involving psychological well-being and gender of the hearing-impaired done by [17] and [18] differences of psychological well-being between genders were found. All these studies, however, have contradicted the studies done by [19] and [20]. Meanwhile, [21] found that genetic excuse (parents status of hearing) did have a significant association with the students' psychological well-being.

In [22] examined the connection of emotional intelligence with adolescent's psychological well-being (depression and self-esteem). They found significant positive relationship between variables of emotional intelligence and self-esteem but showed negative association between emotional intelligence and depression. They concluded that emotionally intelligent people adopt flexible patterns of life, which allow a person to adopt attitudinal changes, which protect a person to feel failure, neglected and development of depression. Their study found that a stepwise structural chain exists between emotional intelligence and life success.

Another research was done by [23] which involves emotional intelligence and psychological well-being. Their study aimed to identify the relationship between emotional intelligence, personality and array of indicators of psychological well-being among law students. In this study, 43 students had completed all tests. The test instruments comprised of emotional intelligence test, personality test, coping test and social well-being test. The findings showed that emotional intelligence was significantly related to three of the six variables that were chosen to represent psychological health and the Big Five personality factor of neuroticism was found to be the strongest predictor of well-being. However, it seems that emotional intelligence does not relate to the additional variance in well-being over personality.

According to [24] also stressed on the relationship between emotional intelligence and psychological wellbeing among students. One hundred students were randomly selected for this study. There were 2 scales that had been utilised in this study namely Well-Being Manifestation Measure Scale and Emotional Intelligence Scale. Their findings showed that there was a significant positive correlation between emotional intelligence and psychological well-being indicating that higher emotional intelligence level will lead to higher psychological well-being level. The findings also indicated that girls are more intelligence than boys.

Meanwhile, a study focusing on the same topic but using different setting and sample was conducted by [25]. In this scenario, the researcher had selected 75 males and 75 females from public and private medical college. The scale of emotional intelligence and psychological well-being were used in this study. Result showed that the emotional intelligence and psychological well-being has significant differences on dimensions of psychological well-being (autonomy, environmental mastery and personal growth) and has insignificant differences on three dimensions of psychological wellbeing (positive relations, purpose in life and selfacceptance) among private and public college.

\section{Method}

\subsection{Research design}

The study utilised a quantitative approach via crosssectional survey by distributing questionnaires to hearing-impaired students from four polytechnics in Peninsular Malaysia.

\subsection{Population and sample}

The population consists of hearing-impaired students at five polytechnics in Peninsula Malaysia. There are a total of 167 hearing-impaired students in five polytechnics in Malaysia. These polytechnics provide special courses to students with hearing-impaired disability (four are situated in Peninsula Malaysia and one in East Malaysia). However, only four polytechnics in Peninsula Malaysia were chosen. Based on the four polytechnics, the population is 139 students. These consist of male and female hearing-impaired students in all semesters from all courses.

Based on [26] table, a total of 103 respondents are needed for a population of 139 students. For this study, a total of 130 respondents $(57$ [43.8\%] male and 73 
females [56.2\%]) were chosen through simple random sampling. The breakdowns of samples are as follows: Ungku Omar Polytechnic (17 respondents), Shah Alam Polytechnic (16 respondents), Sultan Ibrahim Polytechnic (68 respondents) and Tuanku Syed Sirajuddin Polytechnic (29 respondents).

\subsection{Instruments}

The Bar-On Emotional Quotient: Short (EQ-i:S) by Reuven Bar-On [11] and translated by [27] was utilised to measure emotional intelligence. The measurement consists of five dimensions namely intrapersonal, interpersonal, adaptability, stress management and general mood with a five-point Likert scale type response $(1=$ very seldom or not true of me, to $5=$ very often of me or true of me). The internal reliability Cronbach Alpha value for each dimension in this study are as follows: intrapersonal (0.96), interpersonal (0.94), adaptability (0.94), stress management $(0.93)$, general mood (0.93), and overall EQ (0.82).

To measure psychological well-being, the Ryff's Psychological Well-Being by [14] which consist of 42 items was used. It combines the dimensions of selfacceptance, positive relations with others, autonomy, environmental mastery, purpose in life and personal growth. A seven-point Likert type scale were employed to gather responses $(1=$ Strongly disagree, to $7=$ strongly agree). The internal reliability for this measurement is 0.95 .

\subsection{Data analysis}

Data has been analysed through the Statistical Packages of the social sciences version 21. Descriptive and inferential statistics were employed for these purposes.

\section{Results and Discussion}

\subsection{Level of emotional intelligence}

Table 1 depicts the level of emotional intelligence among the hearing-impaired students. A total of 116 respondents $(89.2 \%)$ have moderate emotional intelligence while those with low emotional intelligence consist of 7 respondents (5.4\%) as well and those with high emotional intelligence which consist of 7 respondents $(5.4 \%)$.

Table 1: Level of emotional intelligence

\begin{tabular}{lcc}
\hline & Frequency & $\begin{array}{c}\text { Percentage } \\
\text { \% }\end{array}$ \\
\hline High & 7 & 5.4 \\
Moderate & 116 & 89.2 \\
Low & 7 & 5.4 \\
Total & 130 & 100 \\
\hline
\end{tabular}

Based on Table 1, it seems that the majority of hearing-impaired students achieved moderate and high level of emotional intelligence compared to a small number that achieve low level of emotional intelligence.
This could be due to lower self-esteem based on communication barrier. Nevertheless, the figure is not alarming since less than $10 \%$ have low emotional intelligence.

Being far from home and studying in an environment with normal students is not without difficulties. Hearingimpaired students sometimes have lower self-esteem compared to normal students. Therefore, having moderate emotional intelligence is good enough for sustaining their normal individual life.

\subsection{Level of psychological well-being}

For psychological well-being, a total of 25 respondents (19.2\%) have high psychological well-being compared to 89 respondents $(68.5 \%)$ that have moderate psychological well-being and 16 respondents (12.3\%) with low psychological well-being (Table 2).

Table 2: Level of psychological well-being

\begin{tabular}{ccc}
\hline & Frequency & $\begin{array}{c}\text { Percentage } \\
\text { \% }\end{array}$ \\
\hline High & 25 & 19.2 \\
Moderate & 89 & 68.5 \\
Low & 16 & 12.3 \\
Total & 130 & 100 \\
\hline
\end{tabular}

The well-being of the hearing-impaired students was also at the moderate and high level in terms of psychological well-being. They are neither in the positive or negative state of emotional and social level or self-complacent. Their overall well-being is deemed satisfactorily. Individual with disabilities are those without demanding attitude. They are satisfied with their life and it is somehow subjective in terms of satisfaction if compared to normal individual. Thus, sense of being grateful with their surroundings is one of the attribute of hearing-impaired individual.

\subsection{Relationship between emotional intelligence and psychological well-being}

Bivariate correlational analysis using Pearson correlations has been utilised to determine the association between dimensions of emotional intelligence and psychological well-being. The matrix is shown in Table 3.

Table 3: Correlations between emotional intelligence dimensions and psychological well-being

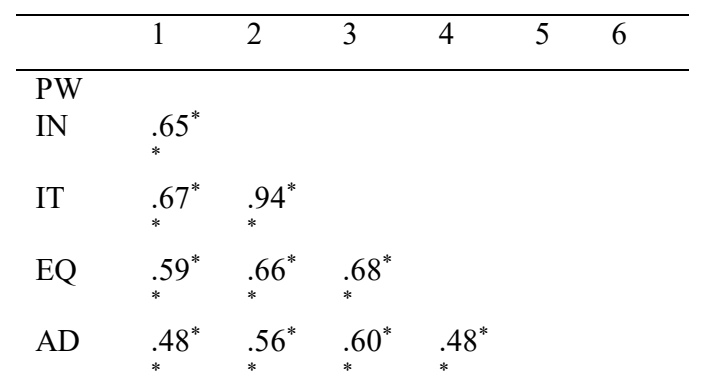




\begin{tabular}{lllllll}
$\mathrm{SM}$ & .18 & .07 & .07 & .13 & .05 & \\
$\mathrm{GM}$ & -.24 & -.22 & -.22 & -.25 & - & -.11 \\
& & & & .05 & \\
\hline \multicolumn{7}{c}{$* p<.05, * * p<.01$}
\end{tabular}

Notes: PW = psychological well-being, IN = intrapersonal, $\mathrm{IT}=$ interpersonal, $\mathrm{EQ}=$ overall

emotional intelligence, $\mathrm{AD}=$ Adaptability, $\mathrm{SM}=$ stress management, $\mathrm{GM}=$ general mood

Based on Table 3, the association between overall emotional intelligence and psychological well-being was found to be significant $(r=0.59, \mathrm{p}<.01)$. This indicates that the higher the level of emotional intelligence among hearing-impaired students, the better the individual psychological well-being.

Results also showed that psychological well-being had a significant association with intrapersonal dimension $(\mathrm{r}=0.65, \mathrm{p}<.01)$ as well as with interpersonal dimension $(\mathrm{r}=0.67, \mathrm{p}<.01)$. This support [22] study that found significant association between emotional intelligence and psychological well-being. In addition, the results are also in line with [23] and [24] studies that found significant relationship between elements of emotional intelligence and psychological well-being.

Hearing impaired students who have better emotional self-awareness, independent and possess adequate sense of assertiveness will be able to achieve better psychological functioning in life. In addition, hearingimpaired students with better social responsibility who manage to establish good relationship with others will also achieve better psychological well-being. Being able to perceive accurately their own emotions and the ability to generate feelings that facilitate their own thoughts are the attributes of those with high intrapersonal and interpersonal elements and this will lead to better satisfaction in individual life.

Finally, adaptability dimension also showed a significant relationship with psychological well-being ( $\mathrm{r}$ $=0.59, \mathrm{p}<.01)$. The higher the adaptability skills they have, the better they will be in terms of psychological well-being. In other words, hearing-impaired students with flexible and open-minded perspective and have better problem solving skills will be better in terms of having positive attitude, better self-awareness and may develop talents and potential to enhance their quality of life. The result support [25] study where elements of emotional intelligence have been found to be associated with elements of psychological well-being.

Being away from home in a new surrounding requires an individual to be adaptive to the environment. Hearing-impaired students in this study have to be able to generate skills and ability to blend with normal hearing individual. With the help of lecturers and colleagues of both normal and hearing-impaired, their overall life satisfaction is enhanced.

\section{Conclusion}

Hearing-impaired students need encouragement and support from communities to enable them to function well in everyday life. Higher emotional intelligence will lead to better psychological well-being in order to carry on with whatever they need to perform in daily life. It is suggested that special workshops or self-emotions training be conducted to these students to alleviate their emotional intelligence skills. As people with disabilities, they should be given the chance to enjoy life to the fullest as normal individual. They are the country's human capital assets. In facts, they could be the unsung heroes with their own special abilities.

The authors wish to thank Universiti Utara Malaysia for funding this study under the university research grant.

\section{References}

1. World Health Organisation,. WHO global estimates on prevalence of hearing loss: mortality and burden of diseases and prevention of blindness anddeafness. http://www.who.int/mediacentre/factsheets/fs3 00/en/index.html (2013)

2. World Health Organisation,. Deafness and hearing impairment. http://www.who.int/pbd/deafness/estimates/en/ (2006)

3. Fatimah, Parents Urged To Discard Fear Of Sending Disabled Children To School. The New Straits Times. https://my.news.yahoo.com/parents-urgeddiscard-fear-sending-disabled-children-school064208255.html (2012)

4. J. Fellinger, D. Holzinger and R. Pollard, Lancet, 379, 1037-44 (2012)

5. M. Jacks, D. Marsh and C. Massey,. Welcome to the Silent Zone Multimedia Courseware on Sign Language. ACM SIGBIO Newsletter, 20, 17-19 (2000)

6. S.D. Antia, K.H. Kreimeyer, (Oxford University Press New York, 164-176, 2003)

7. N. Silvestre, A. Ramspott, I. Pareto, J. D. Stud. D. Edu., 12, 38-54 (2007)

8. Acuna, J.E., R.Q. Bugas, Int. J. Res. Rev., 5, 74-91

http://www.researchgate.net/publication/228347 395 (2010)

9. H. Fazlinda, Employability skills, self-esteem and self-efficacy of technical and vocational students with hearing problems in polytechnics and community college, Malaysia. (Unpublished doctoral dissertation, Universiti Putra Malaysia, 2013) 
10. J.D. Mayer, P. Salovey, App. Pre. Psycho., 4, 197-208 (1995)

11. R. Bar-On, The Bar-On emotional quotient inventory (EQ-i): A test of emotional intelligence. (Toronto: Multi-Health Systems, 1997)

12. W. Pavot, E. Diener, Well- being (inducing life satisfaction). In Rocio, Fernadez-Ballesteror (Eds.) Encyclopedia of Psychological Assessment 2, 1097-1101, (New Delhi: Sage Publications, 2003)

13. S. O. Salami, J. Int. Soc. Res, 3, 387-398 (2010)

14. D. Ryff, Int. J. B. Dev., 12, 35-55 (1989)

15. Keilmann, A. Limberger, W. J. Mann, Int. J. Paed. Otorhino., 71, 1747-1752 (2007)

16. J. Fellinger, D. Holzinger, U. Dobner, J. Gerich, R. Lehner, G. Lenz, D. Goldberg, Soc. Psyc. Psyc. Epid., 40, 737-42 (2005)

17. Weisel, A. Kamara, J. D. Stud. D. Edu., 10, 51$62,(2005)$

18. L. Mejstad, K. Heiling, C.G. Svedin,. A. Ann. D., 153, 504-515 (2009)

19. T. Van Eldik, P. D. Treffers, J. W. Veerman, F.C. Verhulst, A. Ann. D., 148, 390-395 (2004)

20. N. Wolters, H. Knoors, H. N. Cillessen, L. Verhoeven, J. D. Stud. D. Edu., 17, 463-482 (2012)

21. G. S. Palmer, P. Boudreault, E. E. Baldwin, M. Fox, J.L. Deignan, Y. Kobayashi, J. S. Sinsheimer, J. Gen. Coun., 22, $492-507$ (2013)

22. T. Mehmood, S. Gulzar, As. J. Soc. Sc. Human., 3, 178-185 (2014)

23. James, M. Bore, S. Zito, J. Psycho. Ass., 30, 425-438 (2012)

24. S. Shaheen, H. Shaheen, Int. J. Indi. Psycho., 3, 206-213 (2016)

25. S. Irshad, Int. J. Inno. Sci. Res., 15, 50-63 (2015)

26. R.V. Krejcie, D.W. Morgan, Edu. Psycho. Mea., 30, 607-610 (1970)

27. M. Najib, M. Che Su, M. S. Zarina, Res. J. Org. Psycho. Edu. Stu., 1, 93-99 (2012) 